\title{
Como continuar o que inicia: a tripla aporia revolucionária*
}

How to continue what begins: the revolutionary triple aporia

\author{
Etienne Tassin \\ etienne.tassin@univ-paris-diderot.fr \\ (Université Paris VII Diderot, Paris, França)
}

\begin{abstract}
Resumo: A experiência de fundação que orienta a ação revolucionária só pode ser compreendida plenamente quando aceitamos seu único aspecto incontornável: o fracasso. Conforme Arendt sustenta na obra Sobre a revolução (1963), perdidas as tradições política e/ou religiosas que outrora sustentavam os empreendimentos políticos da ação, resta apenas o próprio início como princípio e legado a ser preservado e continuado nos atos de fundação. Surge, assim, a aporia moderna de como efetivar uma experiência que tenta sustentar sua permanência com o início do novo.
\end{abstract}

Palavras-chave: Arendt; início; princípio; revolução; fracasso; aporia.

\begin{abstract}
One can only fully understands the experience of foundation, which directs the revolutionary actions, when an ineluctable aspect of it is taken for granted: the defeat. According to Arendt's On Revolution (1963), once the political and religious traditions that erstwhile grounded political enterprises are lost, the remaining feature is only beginning itself, considered as the principle and the legacy to be preserved and continued in acts of foundation. Therefore, it arises the modern aporia which deals with the way to accomplish an experience of trying to rely its permanence by beginning the new.
\end{abstract}

Keywords: Arendt; beginning; principle; revolution; defeat; aporia.

$\mathrm{Na}$ análise arendtiana da revolução podemos ler não apenas um exame contrastado das revoluções francesa e americana mas, talvez mais essencialmente, uma reflexão sobre o que todo ator revolucionário deve desconsiderar para agir: a saber, toda ação revolucionária está fadada a fracassar. Arendt explicita o sentido deste fracasso, talvez ele próprio o sentido oculto da revolução. Por um lado, ela mostra que a revolução está posta em uma contradição: se ela tem êxito, dá a luz a um aparelho de poder que reproduz a dominação que a revolução achava reverter; se ela fracassa, preserva os atores da dominação mas os priva da liberdade que eles achavam conquistar. Por outro lado, não se pode compreender a revolução em termos de êxito ou fracasso: seu sentido se situa para além do êxito ou do fracasso. O sentido da revolução - a causa da liberdade - não tem nada a ver com sucesso. 
É necessário então pensar a ação revolucionária de maneira não instrumental, não utilitarista e não funcionalista. $E$, portanto, pensar a ação politicamente, ou pensar a dimensão política da ação, é considerar que o que começa com a libertação não pode ser conseguido com a fundação. Nova contradição: sem a fundação da liberdade não há emancipação; e, portanto, toda fundação priva a emancipação de sua liberdade fundamental (liberte foncière).

Trata-se assim de examinar tais dificuldades que compõem a aporia revolucionária interrogando a sua fonte: a definição da ação pela natalidade. Pois o problema da revolução tal qual Arendt o colocou é que o início não inicia nada além do próprio início. Mas como continuar o que assim inicia? Quais instituições, nascidas da revolução, seriam capazes de perseguir seu desígnio sem trair seu espírito? Se, como diz Arendt, a ação revolucionária é na modernidade a ação política por excelência, compreender esta aporia é compreender a própria política.

Examinarei a aporia revolucionária em dois planos: o plano lógico do conceito de início e o plano histórico da interpretação das revoluções. 0 primeiro representa a aporia do início; o segundo, a aporia da continuação do início. Entre os dois, me deterei sobre uma outra aporia que concerne ao princípio de um início sem princípio, à qual Arendt recorre para explicitar a ação revolucionária e pensar em conjunto o início lógico e a continuação histórica.

\section{A aporia lógica do início revolucionário}

A política está fadada a uma aporia insuperável que faz parte da própria natureza da ação. Agir é iniciar, mas iniciar não é comandar: arkhein não é prattein (voltarei a isso) e o poder de iniciar não implica que dispomos do poder de decidir ou controlar a maneira pela qual o que inicia se orienta, prossegue e se realiza. Nenhuma realização está contida no começo. A ação inicia, mas este início não garante que o que ele inicia prosseguirá e se efetivará. 0 início não tem continuação, mesmo que tenha inúmeras consequências. Assim, o que inicia está exposto ao fracasso, não por má condução ou despreparo, mas por definição. Pertence à ação não obter êxito. Do ponto de vista lógico ${ }^{1}$, se fosse exitosa, ela não seria mais da ordem do início, mas da realização, transpassando assim o seu sentido original. E se fica fiel ao seu sentido, aquele do início, então ela não obtém êxito: em sua fidelidade à sua natureza de início, seu êxito a condena a jamais realizar o que ela começa. Para obter êxito, ela deve fracassar.

Mesmo que este paradoxo seja abstrato, é necessário levá-lo a sério. Se um começo compreendesse em si uma indicação sobre a via de sua efetivação, então não

1 Ponto de vista que Arendt, destaco, considera como "abstrato e superficial" (Arendt, 2012, p.530 [Tradução brasileira: 2011, p.283]). 
seria um início (commencement) mas um princípio (début): o princípio de algo que, portanto, conhecesse um meio e um fim. Ou, em seu conceito, o início não principia nada. Ele é aparecimento, pura espontaneidade, diz Arendt. Se ele é aparecimento de algo que outrora não existia, este aparecimento não é o momento inicial do que deve acontecer - e o qual não poderíamos de maneira retrospectiva retomar in statu nascendio surgimento, como se pudéssemos ler nos primeiros momentos as promessas que ele fosse logo efetivar. Apenas uma vista retrospectiva pode, por uma ilusão historicista, crer que o que detectamos de partida no começo - uma vez que a sequência de eventos foi estendida diante nossos olhos - figuraria inicialmente como uma promessa de realização. Nada é prometido no início. Ou tudo! Falando rigorosamente, deveríamos dizer que nada além do início inicia no início, mesmo que o início não comece nada além de si próprio.

Sentimos que ficamos neste lugar à beira do abismo. Pois o que é na modalidade do início não é propriamente falando. É como o aparecimento do ser, um aparecimento cujo futuro não só não está lançado, mas cujo próprio presente não está garantido. O que inicia não tem duração garantida, seria só um instante. E o que iniciou dura o suficiente para parecer prolongar o início que já não se encontra mais no início, mas já em uma forma de efetivação, ela mesma indeterminada. O que inicia não se apresenta, não advém à presença, falta tempo; ou, poderíamos dizer, só se mostra como o que se ausenta em sua própria revelação. 0 antiontologismo radical de Arendt consiste em ficar rigorosamente na evanescência do que se apresenta como aquilo que não tem nem duração nem ser. Pois o que surge ou ocorre sem durar não possui nem ser e nem tempo. Mas, no entanto, ocorre. Como existe - de que maneira - o que é sem ser, sem durar, sem instalação no tempo?

A ocorrência da ação ou do evento é uma aparição; e toda aparição é tomada, ao aparecer, na iminência do seu desaparecimento. Todo nascimento é um aparecimento no mundo; e toda morte é um desaparecimento do mundo. Aparecer é nascer: todo aparecimento é um nascimento de algo ou de alguém². Assim a ação é um aparecer, isto é, nascer. Mas o aparecimento das ações - que também é o nascimento dos atores, da rede de atores e do mundo dos atores - só existe para aquelas e aqueles que a apreendem; e aquelas e aqueles que apreendem, espectadores, são indissociáveis daquelas e daqueles que agem. Na verdade, a divisão entre atores e espectadores é ainda uma maneira didática de mostrar a aparição como modo de ocorrer da ação, e que, por outro lado, as ações existem unicamente de aparecer e de aparecer a uma "comunidade" de atores/espectadores, a qual só existe em

\footnotetext{
2 Notaremos que a noção de natalidade, nome que Arendt reserva ao princípio de início, não leva com ela quaisquer conotações de nascimento no senso biológico, pois ela designa como início tanto a ausência de concepção inicial e de gestação progressiva quanto a ausência de futuro determinado do que nasce ou quanto à possibilidade inevitável do que vem à luz e cresce ou imediatamente desaparece.
} 
razão deste aparecer. Atores e espectadores não preexistem às aparições e não sobrevivem aos desaparecimentos. O que significa que as ações fazem nascer as comunidades de atores/espectadores, pluralidade reunida pelo agir. Mas estas comunidades, entendidas no seu nascimento, isto é, em seu início, não têm muito mais consistência ontológica ou sociológica do que os próprios começos que elas sucedem. Elas não estão mais inscritas no tempo, no qual o seu início the confere futuro. Elas existem no presente, mas um presente evanescente, cuja presença é suspensa no agir, aparecimento e desaparecimento misturados. Assim como a liberdade que manifesta suas ações, elas não existem nem antes nem depois das ações, elas não sobrevivem. Antes de começar, estas comunidades de atores - pluralidade de atores e espectadores ligados uns aos outros na e pela ação - não têm mais futuro do que passado pelo simples fato de começarem. Elas não têm história e só a terão, se alguma vez tiveram uma, pelas histórias que contaremos delas. Elas só entram na história em razão dos contos dos quais serão objeto.

Neste quadro onde conta apenas o presente do surgimento e a presença do que se desfaz assim que nasce, nós devemos nos perguntar: o que nasce? 0 que começa com a ação? O que nasce dela? E como o que nasce pode perdurar?

Se, com toda radicalidade, pensamos a ação sob a categoria do início, então é preciso se ater a duas armadilhas do pensamento que se mantêm em relação a arkhein e prattein. A primeira armadilha vem dissociar, como o fez Platão, as duas dimensões do início (arkhein) e da realização (prattein) de sorte que o início se torna um ato de autoridade, um comando, dispensado pelo agir, pois a própria ação, rebaixada ao cumprimento ou realização, é reduzida a uma execução efetivada pela obediência ou submissão. Dissociando arkhein e prattein, Platão diferenciou duas atividades inicialmente confundidas, empreender ("iniciar", portanto) e agir (tornado, desse modo, "cumprir”), e assegura que o ato de comandar, que inicia, se subordine ao ato de executar, que cumpre a tarefa. Assim, a ação perdia sua virtude própria de iniciar algo de novo ao mesmo tempo em que ganhava a garantia de sua realização na forma da relação comando/obediência ou ordem/execução. Deste modo se encontrava definida uma maneira de comando que daria razão à relação governante/governado que ilustra a oposição entre quem sabe sem agir e quem age sem saber (cf. Arendt, 2012. p.239 [2015, p.272]). É sempre contra esta relação de poder que se levantam os insurgentes.

A segunda armadilha vem, ao contrário, condensar na ideia de início segundo Arendt, como significava o termo em sua origem - o princípio que decide de antemão, na sua liberação, o desenrolar da ação, de sua execução e, portanto, de sua realização. Pois o que inicia contém em si, de partida, seu telos que o guia até seu fim. É neste sentido que Heidegger pode dizer que todo início instaura de si mesmo o caminho que o leva à sua efetivação e que exerce assim uma dominação 
sobre o que vem:

Arkhé significa inicialmente aquilo de onde algo sai e dá partida; na sequência, o que simultaneamente, enquanto fonte e saída, mantém influência sobre o outro que sai de si e assim lhe contém, logo, lhe domina. Arkhé significa ao mesmo tempo partida e influência. (...) quer dizer: início e comando (...) arkhé pode ser traduzida por "poder originário" e "origem se implementando como poder” (Heidegger, 1968, p.190).

A arkhé pode ser então interpretada como uma injunção, tal qual indica o comentário que Heidegger faz de Anaximandro em 1941:

A arkhé é de onde algo é derivado; mas do qual algo guarda, no próprio movimento desta proveniência, a determinação de sua vinda e dá sua totalidade àquilo através do qual o aparecimento se orienta. A arkhé é o que abre caminho para a natureza e para o domínio do aparecimento. (...) A arkhé libera o aparecimento e o que aparece, mas de tal sorte que o que ela entrega permanece então detido na arkhé como injunção. A arkhé é o resultado que ordena (Heidegger, 1985, p.140).

Como imaginar que podemos conceber a ação enquanto início sem renovar a distinção de arkhein e prattein - a qual faz a ação cair no âmbito do poder e do comando - nem reproduzir a concepção unilateral de arkhein - que exerce uma influência sobre o que ocorre segundo uma determinação do início enquanto comando? Em suma, como pensar uma ação cujo princípio é iniciar, mas iniciar sem princípio, sem príncipe nem autoridade?

Sabemos que a ação revolucionária é dupla: ela derruba o antigo regime e instaura uma nova ordem, ou seja, libera do antigo julgo e funda um espaço de liberdade: libertação e fundação. Mas ela se encontra confrontada com três problemas: uma violência inevitável, uma autoridade incapaz e um futuro indeterminável. A ação revolucionária é violenta: o começo só pode se privar da violência se desfeita a antiga ordem e instalada uma nova (eu deixarei este ponto de lado). A ação revolucionária é infundada: o início não pode se valer da antiga autoridade, pois ela foi rejeitada para começar, nem invocar outra autoridade que não seja seu próprio ato fundador, pois ela é puro começo. A ação revolucionária é imprevisível: o começo não pode se justificar do que fará ocorrer, pois ele faz o possível, nada nele faz o necessário, o inevitável ou o desejável. Arendt também insiste em indicar que a revolução não poderia aparecer aos revolucionários de outro modo que não fosse um hiato "entre fim e início, entre o que não é mais e o que ainda não é". Nesta "lacuna do tempo histórico" entre o que não é mais e que ainda não é, o início comporta "uma dimensão totalmente arbitrária": ele surge do nada e não indica nenhuma direção determinada. Por um momento, o momento do início, é como se o iniciador tivesse abolido a própria sequência da temporalidade ou como se os atores fossem lançados fora da ordem temporal e de sua continuidade (cf. Arendt, 2012, p.514 [2011, p.264]). 
Ao arbítrio do início estariam inevitavelmente associadas uma violência inevitável, uma autoridade incapaz e um futuro indeterminado. A ação revolucionária só escaparia do comando de um poder arcôntico, tal qual pensa Heidegger, por exemplo, entregando-se a uma potência anárquica. Se é “inútil buscar um absoluto para sair do círculo vicioso em que todo início se encontra necessariamente preso, sabendo que este absoluto reside no próprio ato de iniciar" (Arendt, 2012, p.513 [2011, p.262]), a absolutização do início daria razão à força irruptiva apenas porque ela irrompe?

\section{A aporia de princípio de um começo an-árquico}

Conhecemos a resposta arendtiana: invocar o princípio que inicia com o início e cujo início é o princípio. Resposta, contudo, delicada e difícil. Permitam-me citar um pouco longamente esta passagem onde ela apresenta esta resposta:

O que salva o ato de iniciar de sua própria arbitrariedade é que ele traz dentro de si seu próprio princípio, ou, em termos mais precisos, que o início e o princípio, principium e princípio, não só estão relacionados entre si mas são simultâneos. 0 absoluto do qual o princípio há de derivar sua validade e que, por assim dizer, deve salvá-lo de sua arbitrariedade intrínseca é o princípio que faz seu aparecimento no mundo junto com ele. A maneira como o iniciador começa o que pretende fazer estabelece a lei da ação para os que se uniram a ele a fim de participar e realizar o empreendimento. Como tal o princípio inspira os atos que se seguirão e continua a aparecer enquanto dura a ação. (...) Pois a palavra grega para início é arkhé, e arkhé significa ao mesmo tempo o início e o princípio (Arendt, 2012, p.521 [2011, p.272]).

E de citar Platão lhe parafraseando: “Pois o início, porque contém seu próprio princípio, é igualmente um deus que enquanto reside entre os homens, enquanto inspira seus atos, tudo salva". ${ }^{3}$

Somos convidados a pensar um começo que salva porque é princípio ou é, ao menos, indissociável de um princípio que aparece com ele e inspira os atores; contudo, um princípio que não comanda e que, se gera autoridade, não é autoritário. Devemos então reter duas coisas. É preciso reconhecer, por um lado, como escreveu Reiner Schürmann, que nos eventos revolucionários opera-se um corte, esta brecha no tempo que Arendt evoca, durante a qual tanto o princeps (o governo) quanto o principium (sua autoridade sistêmica) são suspensos de modo que

O campo político se enche plenamente de seu papel de revelador: ele manifesta aos olhos de todos que a origem do agir, do falar e do fazer não é um ser (sujeito, ser-aí ou objeto); não é uma arkhé, início e comando de um tornar-se que dura; não é um princípio que domina e organiza a sociedade, mas que ela é a simples vinda à presença de tudo que é presente. Destas cisões mostra-se que a origem não "inicia"

3 Platon. Les Lois, VI, 775: "arkhè gar kai theos em anthrôpois idrumenè sôzei panta“, apud Arendt, 2012, p.521.[2011, p.272]. 
nada... (Schürmann, 1982, p.107, grifos meus) ${ }^{4}$

Simples vinda à presença, simples manifestação sem qualquer arkhé: então, o que se apresenta, se manifesta, não carrega consigo uma injunção a priori do que deve acontecer. Portanto, por outro lado, devemos admitir segundo Arendt que o princípio "inspira”, que a via tomada pelo ator ao iniciar "dita” o caminho àqueles que agem em concerto de modo que a ação se dirige à efetivação, que o começo se prolonga em uma certa realização do que começou.

Arendt fica, portanto, em um lugar estreito: ao salientar, por um lado, que o início recusa a autoridade passada mas também qualquer autoridade, qualquer comando, ela arrisca privar a ação do que the confere sentido, de the conferir a imagem de uma força pura surgida de parte alguma que não produz nada de promissor, em suma, uma anarquia insignificante; ao retomar, por outro lado, o tema heideggeriano do comando, ela o privaria de sua total liberdade, de seu caráter fundamental anárquico. Ela precisa então ao mesmo tempo defender o caráter anarquico do início e lhe apoiar em um princípio que seja, como ela diz, o absoluto do qual tira sua validade.

A solução adotada por ela é delicada e significativa. Para pensar o início, ela convoca a noção de princípio, mas esvazia sua dimensão autoritária, literalmente principial (principielle): ela faz dele um princípio sem príncipe, sem principado. Do princípio, ela mantém à maneira platônica - a qual, por outro lado, ela condena devido à sua filosofia política arquetípica - que o início, por conter em si seu próprio princípio, é um “deus que salva” e inspira os atos. Precisamos compreender que o princípio que aparece com a ação não comanda esta última. Ao invés do princípio comandar a ação, é esta, ao contrário, que o torna visível, que o manifesta. 0 princípio está atado à ação que the torna visível e se manifesta enquanto dura a ação; nem antes nem depois (cf. Arendt, 1972, p.200. [2008, p.199). O princípio inspira os atores deixando claro para eles o sentido de suas ações e é saudável enquanto inspira os atores.

Que princípio é este contido no início e que, contudo, não é uma arkhè, um comando? Vejo apenas uma resposta possível a esta questão que satisfaça a exigência formulada por Arendt através do recurso do início. 0 princípio próprio ao início é o princípio do início. Para um ouvido distraído esta resposta parece uma tautologia. Ela não é. Por um lado, esta ideia de princípio exprime a ponta mais extrema do antiontologismo arendtiano: "initium ergo ut esset, creatus est homo." Os homens

\footnotetext{
4 Schürmann faz referência explícita a Arendt ao evocar as "reuniões de cidadãos na América por volta de 1776, as 'sociétés populaires' de Paris entre 1789 e 1793, a Comuna, os sovietes de 1903 e 1917, a Democracia de Conselhos na Alemanha em 1918 - todos esforços modernos analisados por Hannah Arendt em referência ao modelo americano a fim de livrar o domínio público da força coercitiva" (Schürmann, 1982, p.107).

5 "Para haver um início, deus criou o homem" (Agostinho, Cidade de Deus, XII, 20 - ver Arendt, 2012, p.520 [2011, p.270]).
} 
não têm simplesmente o direito de poder iniciar: eles são um poder de iniciar, eles são inícios porque são “iniciadores”, precursores. Ser é iniciar e iniciar (agir) é aparecer e, assim, manifestar sua liberdade. O início é o princípio da ação pois a ação é o modo de manifestação da liberdade humana. Toda revolução ganha, portanto, o sentido de produzir (no duplo sentido de apresentar, tornar visível e de engendrar, fazer nascer) esta liberdade e sua cena de aparecimento. Os seres humanos são

Capacitados para a tarefa, que é um paradoxo em termos lógicos, de criar um novo início, porque eles mesmos são novos inícios e, portanto, iniciadores, que a própria capacidade de iniciar se radica na natalidade, no fato de que os seres humanos aparecem no mundo em virtude do nascimento (Arendt, 2012, p.520 [2011, p.270]).

Por outro lado, o princípio diz essencialmente: porque toda ação inicia algo, a política diz respeito a inícios e o sentido de toda ação é iniciar e preservar a possibilidade dos inícios, isto é, a possibilidade da liberdade. Toda ação visa o início como seu fim. ${ }^{6}$ Nós agimos (isto é, nós iniciamos) para que se liberem os inícios e os espaços para estes inícios, bem como as cisões temporais para estes inícios e as brechas na continuidade do tempo. O que salva a ação nos inícios é que o início jamais renuncia ao início; ou, dito de outro modo, pois os termos são intercambiáveis: a ação visa sua própria recondução enquanto ação; o início tem por finalidade implantar o espaço e o tempo de possíveis reinícios. Todo início que não visasse a instauração de possíveis (re)inícios contradiria seu princípio e condenaria a revolução ao fracasso. De modo que a efetivação da ação que Arendt evoca só pode ser a efetivação enquanto início e não seu acabamento em alguma realização ou perfeição. É precisamente este princípio do início próprio à ação - princípio de ação política em geral que encarna por excelência a ação revolucionária - que condena a revolução ao fracasso.

\section{A aporia histórica da continuação da revolução}

Na medida em que o maior acontecimento em toda revolução é o ato de fundação, o espírito da revolução contém dois elementos que nos parecem irreconciliáveis, e até contraditórios (Arendt, 2012, p.530 [2011, p.283]).

O ato de fundação do novo corpo político exige a instituição estável e perene de uma nova forma de governo a fim de garantir as liberdades conquistadas, mas aqueles que se engajaram na ação revolucionária tiveram "a experiência de uma percepção revigorante da aptidão humana a iniciar algo" (Arendt, 2012, p.530 [2011, p.283]). A questão da estabilidade entra em contradição com o espírito inovador. Face a esta contradição, os Pais Fundadores da Revolução Americana sentiram “o desejo urgente

6 Ou, em termos arendtianos, o início é ao mesmo tempo a condição sine qua non e a condição per quam da ação. 
de assegurar a estabilidade de sua criação e de estabilizar cada um dos fatores da vida política em uma 'instituição durável'” (idem, p.536 [idem, p.291], grifos meus). Era necessária uma instituição que fizesse durar o início. Eles conceberam o Senado como esta instituiçãa destinada a preservar tanto a pluralidade de discursos e de atos quanto a pluralidade de opiniões políticas; e a Corte Suprema como uma outra instituição destinada a preservar a pluralidade de juízos de justiça, ambas contra a tirania da opinião pública. Mas este desejo e este cuidado fracassaram. Aos olhos de Arendt, ao contrário, notável é "a falha da revolução em fornecer uma instituição duradoura" (idem, p.538 [idem, p.294], grifos meus), como se aqueles que trouxeram a república "tivessem esquecido o que mais tinham no coração: as potencialidades da ação e o privilégio distinto de se engajar em uma obra sem precedente" (idem, ibidem).

Como continuar o que inicia se a ação que começa e rompe a continuidade histórica não é uma ação que continua e se a continuação que tenta prolongar o começo é simultaneamente uma ordem de efetivação (continuidade) e de realização (autoridade)? A antinomia do início e da continuação cria uma verdadeira aporia pois é o espírito do início que exige a instituição durável e esta - a instituição durável exigida pelo início - que contradiz aquela.

O problema era muito simples e, formulado em termos lógicos, parecia insolúvel: se a fundação era o objetivo e o fim da revolução, então o espírito revolucionário não era apenas o espírito de iniciar algo novo, e sim o de começar algo permanente e sólido; uma instituição duradoura, encarnando e incentivando este espírito a novas realizações, seria autodestrutiva. Daí infelizmente parece decorrer que não existe ameaça mais perigosa e mais aguda contra as próprias realizações da revolução do que o espírito que as empreendeu. Teria de ser a liberdade em seu sentido mais elevado de liberdade de agir, o preço a pagar pela fundação? (Arendt, 2012, p.539 [2011, p.294])

$\mathrm{Na}$ realidade, o espírito do início - o espírito revolucionário - é animado por um desejo duplamente magnético e contraditório: por um lado, o desejo de começar algo novo; e por outro, o desejo de que o que começa seja durável (perene e sólido). Estas duas dimensões do desejo revolucionário se neutralizam, tal é o paradoxo aporético da revolução. 0 espírito revolucionário que suscita o início faz fracassar sua continuação; e o espírito conservador que impulsiona a precaução com a estabilidade contradiz o desejo de iniciar algo novo. Thomas Jefferson ilustra para Arendt as hesitações dos homens da revolução diante desta aporia. Antes da experiência da Revolução Francesa, Jefferson se opõe à pretensão de a Constituição ser imutável, chegando a valorizar as rebeliões que a questionavam e manifestava que os novos homens continuassem a agir livremente - iniciar - contra a instituição durável que lhes privava da sua liberdade. "A árvore da liberdade precisa ser regada, 
de tempos em tempos, com sangue de patriotas e tiranos. É seu adubo natural"'. A preocupação em conciliar início e continuação se traduz pela liberdade oferecida às gerações futuras de contestar a Constituição, pois as instituições criadas pela revolução não são suficientes para assegurar ao povo uma arena onde manifestar sua liberdade: discussões, deliberações, decisões e contestações permanecem prerrogativa dos seus representantes: "como preservar o espírito revolucionário uma vez que a revolução chegue a seu fim?” (Arendt, 2012, p.545 [2011, p.301]) Falta integrar na Constituição as arenas locais da ação política onde o povo pode iniciar o novo, a saber, os municípios e assembleias municipais. A Constituição terminou por confiscar a revolução, suprimindo os inícios em benefício da continuidade.

Por paradoxal que possa parecer, de fato foi sob o impacto da revolução que o espírito revolucionário na América começou a definhar e foi a própria Constituição, essa grandiosa realização do povo americano, que acabou por defraudá-lo de seu bem mais precioso (Arendt, 2012, p.545 [2011, p.302]).

Toda leitura arendtiana da Revolução Francesa é impulsionada por este mesmo espírito de interpretação: o conflito do governo e do povo é um conflito entre a preocupação com a estabilidade das instituições e o espírito inovador da ação popular. A condenação das sociedades populares e a submissão da Comuna de Paris significam a vitória do governo contra o povo, o que é a vitória da continuidade sobre os inícios ao mesmo tempo que a vitória das instituições sobre as ações. 0 conflito entre governo jacobino, confiscando em seu proveito o privilégio do poder, e as sociedades revolucionárias, as quais perpetuam os inícios e renovam a cada dia as formas de ação coletiva, é também um conflito entre a pretensão governamental de exercer o poder e o civismo das sociedades populares que revive constantemente o bem público.

A instituição do poder depois das forças revolucionárias contradiz o poder popular nascido, surgido, afirmado na manifestação destas forças através das ações de liberação e experimentadas livremente no seio das sociedades populares, dos municípios e das comunas. Pois a oposição do começo e da continuação encontra uma solução histórica na experiência da Comuna ou do Conselho e não nos partidos ou os aparelhos de poder. A solução lógica para a aporia é manter vivo, sob uma forma institucional apropriada, o poder dos começos: ela requer uma instituição que, durável, preserve dentro de si não as conquistas da revolução mas seu princípio, o espírito dos começos que é um espírito insurrecional. Mas o que seria uma instituição durável fadada a prorrogar o começo do novo, isto é, da insurreição? Todas as soluções históricas da aporia - as sociedades populares, as Comunas, o sistema de conselhos - fracassaram. Paradoxalmente, a razão deste fracasso, dirá Arendt, não

7 Carta de Th. Jefferson ao Coronel W. St. Smith datada de Paris, 13 de novembro de 1787, cf. Arendt, 2012, p.540 [2011, p.295]. 
é nem falta de preparo dos revolucionários nem mesmo o destino que thes reservou partidos e aparelhos de poder, mas mais fundamentalmente as elevadas qualidades políticas dos atores desta história. Ao se ater fielmente ao espírito dos começos, eles se impediram de fazer durar estes começos. Pois, é infelizmente fazendo fracassar o desejo de começar algo de permanente e durável que eles puderam honrar seu desejo de começar algo novo. Evocando os conselhos da revolução húngara, ela escreve que "a causa principal do seu fracasso não era a anarquia dos cidadãos, mas as suas qualidades políticas", enquanto que

A razão pela qual os aparatos partidários, apesar de inúmeros defeitos - corrupção, incompetência, desperdício inacreditável -, acabaram se saindo bem onde os conselhos haviam falhado residia exatamente em sua estrutura original oligárquica e até autocrática, a mesma que os fazia tão absolutamente inconfiáveis para todos os fins políticos (Arendt, 2012, p.579 [2011, p.343]).

Também é preciso opor aos aparelhos de governo centralizados a multiplicação de espaços públicos plebeus (cf. Breaugh, 2007), bem como lugares de aparecimento para novos começos. Assim, “o espírito da revolução - um espírito novo e o espírito de iniciar algo novo - [que] não conseguiu encontrar uma instituição que the seria apropriada" (Arendt, 2012, p.586 [2011, p.349]). Na hora das grandes revoluções da época moderna será preservado e o tesouro perdido das revoluções poderá renascer, como a fada Morgana que, diz Arendt, sempre reaparece quando acreditávamos haver desaparecido.

Tradução de Paulo Eduardo Bodziak Junior.

\section{Referências}

Arendt, H. (1972). “Qu'est-ce que la liberté?”. In: La crise de La culture. Paris: Gallimard. [Tradução brasileira: Arendt, H. (2008). “O que é liberdade?”. In: Entre o passado e o Futuro. Tradução de Mauro Barbosa de Almeida. São Paulo: Perspectiva.]

. (2012). "Condition de l'homme moderne”. Traduit par G. Fradier. In: L'humaine condition. Paris: Gallimard. [Tradução brasileira: Arendt, H. (2015). A Condição Humana. Tradução de Roberto Raposo; revisão técnica e apresentação Adriano Correia. São Paulo: Forense Universitária.]

. (2012). "De la revolution”. Traduit par M. Berrane. In: L'humaine condition. Paris: Gallimard [Tradução brasileira: Arendt, H. (2011). Sobre a Revolução. Tradução de Denise Bottmann. São Paulo: Companhia das letras.]

Heidegger, M. (1968). “Comment se determine la physis ?” In: Questions II. Traduit par F. Fédier. Paris: Gallimard. 
Etienne Tassin Gallimard.

(1985). Concepts fondamentaux. Traduit par Pascal David. Paris:

Breaugh, M. (2007). L'expérience plébéienne: Une histoire discontinue de La liberté. Paris: Payot.

Schürmann, R. (1982). Le príncipe d'anarchie: Heidegger et laquestion de l'agir. Paris: Seuil.

Recebido em: 22.10.2015

Aceito em: 16.11.2015 